that 1 per cent is the maximum concentration of glycerol which unfrozen fowl semen will tolerate without losing fertilizing capacity, and in this concentration only an occasional spermatozoon survives freezing to $-79^{\circ} \mathrm{C}$. Nevertheless, out of six hundred eggs laid by hens which had been inseminated with semen frozen in the presence of 1 or 2 per cent glycerol three chicks were hatched, and one embryo died between the fifth and eighteenth day of incubation. It seems likely, therefore, that the very fow spermatozoa which survive freezing under these conditions retain their fertilizing power. The possibility is now under investigation that, as in the experiments of Shaffner ${ }^{11}$, a considerable proportion of eggs were fertilized by frozen and thawed spermatozoa, but that the embryos died in the early stages of development. Attempts have been made to reduce the concentration of glycerol required to protect fowl spermatozoa against low temperatures, or to prevent its adverse effects on fertilizing power, by incorporating other substances in the diluting fluids.

Among the substances tried are lecithin, egg yolk, egg white, milk, glucose, fructose, mannose and other sugars, and different buffer substances and colloids. So far, no diluent more effective and less harmful than glycerol in Ringer's solution has been found. With propylene and ethylene glycol a concentration of 6 per cent in fowl semen permits normal fertility of unfrozen material; after freezing in this concentration, however, few spermatozoa are active, and the semen is infertile. A concentration of 10-20 per cent of these substances severely reduces the fertility of unfrozen semen, so that after insemination only three fertile eggs were obtained out of four hundred laid by pullets. . Two live chicks and one dead embryo were obtained, however, from about the same number of eggs laid by hens inseminated with frozen semen.

The mechanism by which these substances reduce the fertility of fowl semen is being studied. With the semen of mammals reduced fertilizing power is often associated with low oxygen consumption ${ }^{12}$. Preliminary metabolism studies indicate that glycerol reduces the oxygen consumption of fowl spermatozoa at $25^{\circ} \mathrm{C}$. to a level which is not further reduced by subsequent freezing and thawing. This adverse effect of glycerol on the fertilizing power of spermatozoa does not appear to be general. Rabbit semen diluted with 20 per cent glycerol in 0.25 per cent gum arabic, or 30 per cent glycerol in methyl cellulose, has been used for insemination and shows unimpaired fertilizing capacity; but so far only one fertile egg has been found among fifty-three recovered from the does inseminated with frozen semen. The impaired fertility may be due, in the rabbit, to reduced motility of the semen when thawed. As regards other species, there are special difficulties with other laboratory animals for work involving artificial insemination. Experiments have been started with cattle; but progress is bound to be slow.

A number of interesting problems are raised by this work. First, the harmful effects of changes in the medium during freezing and thawing must be considered, and distinguished from those of changes in the cell itself. Alterations in the medium might damage spermatozoa by mechanical effects such as pressure and tension during crystallization and thawing, or by physicochemical means such as altered tonicity during and after removal of water as ice. Glycerol in the medium appeared to reduce mechanical damage; but whether it altered the physical and chemical state of the electrolytes and non-electrolytes after they had been concentrated by freezing, so as to reduce their harmful effects on the cells, is not clear. Changes within the spermatozoa must be even more complicated, and probably vary from species to species. Our microscopic studies of freezing amoebæe support Luyet's view that a cell has little chance of surviving if free water crystallizes within it to form ice. Spermatozoa may, however, have a low content of free water, and it seems that the risk of intracellular ice formation due to slow cooling is less important than the deleterious effects of rapid temperature changes which are known as temperature shock in the range above zero ${ }^{12}$ and seem also to operate in some form in a range far below. Secondly, the possibility that chemical and physical agents including temperature change have different effects on different parts or functions of the same cell must be borne in mind. The action of glycerol on spermatozoa is obscure, and whether it influences the permeability of the cell membrane or whether it penetrates into the cell is not known. It is clear that in some species glycerol exerts a different effect on the midpiece and tail which are responsible for motility, and on the head which is directly concerned with fertilizing the ovum. Thus, media containing glycerol in high concentrations support good motility of fowl spermatozoa but reduce their oxygen consumption and fertilizing capacity, whereas with rabbit spermatozoa glycerol reduces the motility but not the fertilizing power of the unfrozen semen. The exact nature of these changes remains to be elucidated.

We are indebted to our colleague Dr. D. Herbert for carrying out the metabolism experiments on fowl spermatozoa.

${ }^{1}$ Luyet, B. J., and Gehenio, P. M., Biodynamica, 3, 33 (1940).

${ }^{2}$ Weinman, D., and McAllister, J., Amer, J. Hyg., 45, 102 (1947).

s Breedis, C., J. Exp. Med., 76, 221 (1942).

- Rahm, G. K., quoted by Heilbrunn, L. V., "An Outline of General Physiology." 2nd edition (1943). (Saunders, Philadelphia and London.)

${ }^{5}$ Polge, C.. Smith, A. U., and Parkes, A. S., Nature, 164, 666 (1949).

- Smith, A. U., Polge, C., and Smiles, J. (in the press).

${ }^{7}$ Jahnel, F., Klin. Wschr., 17, 1273 (1938).

8 Shettles, L. B., Amer. J. Physiol., 128, 408 (1940).

'Parkes, A. S., Brit. Med. J., ii, 212 (1945).

10 Smith, A. U., and Polge, C., Vet. Rec., 62, 115 (1950).

11 Shaffner, C. S., Science, 96, 337 (1942).

${ }^{12}$ Chang, M. C., and Walton, A.. Proc. Roy. Soc., B, 129, 517 (1940).

\section{PRODUCTION AND UTILIZATION OF CHEMICAL ENERGY}

A DISCUSSION on "Chemical Energy" arranged by Section B (Chemistry) of the British Association was held at Birmingham on September 5 . It was opened by two papers by Prof. F. H. Garner, of the University of Birmingham, one of which served as an introduction to the general theme whereas the other dealt specifically with combustion reactions.

Prof. Garner, in his introductory talk, pointed out that the chemical energy liberated in a reaction may appear in several forms, notably as heat, light or electrical energy. The main sources of chemical energy are those which have been derived originally from the radiant energy of the sun and are stored in natural fossil fuels such as coal, petroleum, shale or peat. These are capital resources and, moreover, wasting assets the energy of which is made available by combustion processes, the liberated heat being used 
as such or converted into mechanical or electrical energy. The transformation of heat into mechanical energy is a process of strictly limited efficiency because of the operation of the Second Law of Thermodynamics, and all heat engines have relatively low efficiencies, usually less than 40 per cent.

Prof. Garner stressed, however, the importance of energy being produced in a convenient form, for this factor is often of greater importance than that of thermal efficiency, and the factor of cost inevitably enters into considerations of energy utilization.

Most of the efficiencies attained in the utilization of chemical energy are extremely low; for the production of industrial power and heat from coal, the average overall efficiency has been calculated to be 17 per cent. Thus, although steam may be generated at thermal efficiencies of $\mathbf{8 5}$ per cent, the conversion to mechanical energy at an efficiency of 35 per cent gives a combined efficiency of only 30 per cent. The conversion of mechanical energy to electrical energy is, however, an efficient process, and consequently the overall efficiency of electricity generation can be as high as 29 per cent. Where heat energy is used at high temperatures, for example, in metallurgical and glass furnaces, efficiencies attained are low since the waste gases are discharged at high temperatures. By employing these hot waste gases for steam generation or for pre-heating the air to be used for combustion of the fuel, or in other ways, much can be done to raise efficiencies.

Liquid fuels are preferred for transport by sea, land and air, due largely to convenience in handling, and ease of flow and control in the power unit itself.

In his second paper, Prof. Garner considered the efficiency in use of the chemical energy from combustion, in heating processes and in its conversion to mechanical and electrical energy.

The use of fuels in their natural state leads to high thermal efficiencies only in a few applications, one of the chief of which is steam raising, where thermal efficiencies of 90 per cent are obtainable in efficient power stations; although only where the steam can be used efficiently can a high overall figure be attained.

In the field of transportation, there are three forms of internal combustion engine: the spark-ignition (petrol) engine, the compression-ignition (diesel) engine, and the gas turbine. The efficiency of sparkand compression-ignition engines depends upon the compression ratio employed. Ricardo showed that unless suitable fuels are supplied for a given value of the compression ratio, 'knocking' occurs with its attendant tendency to pre-ignition, loss in efficiency and possible damage to the engine. In order to enable high compression ratios to be used, aromatics were introduced as the first anti-knock agents ; but later, processes for cracking petroleum were developed. Cracked gases are now largely converted by processes of polymerization, alkylation and isomerization to synthetic hydrocarbons which have made possible the modern high-octane aviation fuels still further improved by the addition of lead tetraethyl.

The diesel engine is thermally more efficient than the petrol engine and is finding increasing use in the larger-size units, as in rail and sea transport.

The thermal efficiency of the motor-car engine is only about 6 per cent in the United States ; owing to the higher cost of fuel in Great Britain, smaller and more efficient engines have been developed. The figure is low, since most of the time the engine is producing power equivalent to less than one-quarter
Ioad. The aircraft engine which operates mainly at full load reaches an efficiency of 12 per cent.

Prof. Garner drew an interesting comparison between the coal-fired steam and the oil-fired locomotive and the diesel-electric locomotive, with thermal efficiencies of 4, 6 and 26 per cent respectively, and pointed out that in the United States this is leading to a rapid replacement of the steam locomotive by the diesel-electric engine for railway purposes.

In conclusion, Prof. Garner dealt with the gas turbine, which for aviation purposes employs kerosene as fuel. The gas turbine does not demand a fuel of high octane or cetane number; but fuels other than clean distillate fuels may lead to deposits on, or erosion of, the turbine blades. In particular, petroleum residual oils of low ash content have led to serious deposits, apparently due to the minute contents of vanadium of the order of 0.04 per cent or less. The future of the larger-sized gas turbines, for which efficiencies of more than 30 per cent are expected, appears to depend on the extent to which the natural fuels, coal and petroleum, can be used.

Dr. James Taylor (Nobel Division, I.C.I., Ltd.) pointed out that there is another important class of chemical reaction which man has harnessed to replace human effort. These diverse exothermic reactions are not economic methods of providing energy except for providing high power for very short intervals of time, or for use under conditions where atmospheric oxygen is not available. Many of these reactions are very violent, as, for example, in high explosives, whereas in other cases the rate depends upon the pressure of operation, and the materials, for example, cordite, can be used as propellants.

The important property of explosives is that they are self-propagating when initiated or ignited from a local point. In the case of high explosives, 'point' initiation is normally provided by a local intense shock or blow as from a detonator, which comprises a small metal tube filled with an explosive such as fulminate of mercury. Initiation in the case of propellants, such as cordite or incendiary mixtures, is usually thermal in character, generally by means of a flame.

Dr. Taylor traced the development of explosives from gunpowder to the detonating explosives in which reaction is initiated and sustained by a mechanical shock wave passing at high velocity through the explosive. Such explosives are of vital importance in civil and mining engineering. For mining purposes, gunpowder cannot be used safely where methane/air mixtures are liable to occur. The position has been completely altered by the advent of detonating explosives; and by the incorporation of cooling materials tike common salt into explosives based on nitroglycerine (or T.N.T.) and ammonium nitrate, the so-called 'permitted' explosives have been developed. In rockets, black powder has been displaced by cordite, and these are now used for the assisted take-off of aircraft; recently increasing attention has been given to the use of propellants as controlled energy sources for performing mechanical operations. The power cartridge field includes cartridges for starting aero engines, for the ejection of pilots from high-speed aircraft in an emergency and for a variety of other purposes.

Gentler types of mixture were also discussed, and reference was made to a cartridge developed for insertion into tinned soup for providing hot refreshment for troops during the War. Another mixture of antimony and potassium permanganate has been 
used in making delay fuses for detonators, and these can be used for controlled blasting.

The decomposition of ammonium nitrate is extremely complex and does not occur readily in normal circumstances; however, certain substances such as potassium chromate or ammonium dichromate, added in quantities of the order of a few per cent, cause the self-sustained decomposition of this substance. Such compositions can be pressed into compact cylinders and will provide gas steadily for long periods. They can be used for driving motors or as fuels for rockets and jet-propelled devices. Guanidine nitrate compositions have been used for operating jet propulsion units for model aeroplanes and motor-cars.

Liquid mono-propellants such as concentrated ( 80 85 per cent) hydrogen peroxide, methyl and ethyl nitrates, nitromethane and other substances were discussed, and the use of the first in the launching device for the German Vl weapon was mentioned. Bi-propellants such as liquid oxygen and alcohols, or concentrated nitric acid and aniline, have been used in rockets of the $V 2$ type.

Dr. Taylor illustrated his lecture by means of a series of carefully executed and spectacular demonstrations which proved to be exceedingly popular with his audience.

The third speaker, Dr. H. J. T. Ellingham (Royal Institute of Chemistry), discussed the direct conversion of chemical energy to electrical energy. He pointed out that a voltaic cell may be regarded as a device for converting the 'free energy' of a reaction into electrical energy. In principle, almost any type of spontaneously occurring chemical reaction is capable of being harnessed in a voltaic cell. In practice, however, few types of reaction have been effectively used in this way, and the operation of practically all established forms of primary cell is based on the oxidation of a metal (generally zinc) to one or other of its compounds. If an efficient cell could be developed to harness the oxidation of carbon, it might provide an alternative means for the large-scale generation of electrical energy from coal. The possibility is attractive, because no upper limit of efficiency is set by the Second Law of Thermodynamics as in the heat-engine stage of the existing process. Even if it proved impracticable to make use of the direct oxidation of coal or coke, there might still be scope for an indirect fuel cell operating on the oxidation of secondary fuels such as hydrogen or carbon monoxide.

Possible reactions were discussed in some detail and it was suggested that metals such as tin or lead, which can be obtained by carbon reduction at relatively low temperatures, would be preferable for use in cells to higher-melting metals or those with much greater affinity for oxygen.

The general form of a fuel cell is

$$
\text { fuel }\left.\right|_{-} \text {electrolyte }\left.\right|_{+} \text {oxygen }
$$

The oxygen would preferably be supplied as air to avoid the cost of separation. During the discharge of such a cell, oxygen ionizes at the positive electrode giving oxygen or oxygenated ions (hydroxyl ions in aqueous solution), while at the negative electrode either the fuel substance ionizes (hydrogen or the metals yielding positive ions) or the oxygen or oxygenated ions in the electrolyte are discharged, forming nascent oxygen which then reacts at the anode surface with the fuel substance.

Neither carbon nor carbon monoxide can furnish corresponding ions, and their use in a fuel cell depends on their being oxidized anodically by nascent oxygen -a reaction which only proceeds at a reasonable rate at an elevated temperature. Oxygen does not give a reversible electrode system as does hydrogen adsorbed on the surface of platinum; however, oxygen diffusion electrodes have been developed, and tem. peratures of more than $200^{\circ} \mathrm{C}$. have been used for hydrogen - oxygen cells in aqueous solution working at pressures up to 55 atmospheres. The fact that raising the temperature increases rates of reaction and diffusion makes the prospects of fuel cells with molten-salt electrolytes seem attractive.

Dr. Ellingham reviewed experimental work upon molten-salt electrolyte fuel cells and suggested that they might be designed to convert more than 30 per cent of the chemical energy to electrical energy.

In conclusion, it was suggested that more attention might be given to the possibility of linking cell reactions consuming secondary fuels with the process of production of the fuel from carbon, in which manner improved heat economy might be attained.

Prof. F. G. Gregory (Imperial College of Science and Technology, London), who concluded the discussion, considered the building up of chemical energy by vegetation, and discussed estimates which have been made of the material turnover in the carbon cycle in terms of the amount of carbon fixed per annum from the atmosphere and oceans.

The amount of solar radiation reaching the earth's surface can be estimated, and an approximate value obtained for the amount of suitable radiation available for photosynthesis. From these results it is possible to deduce a rough value for the efficiency of utilization of solar energy by vegetation, and this is found to be of the order of 1 per cent. The factors controlling photosynthesis were discussed and figures given to show that plants very dissimilar in nature assimilate at the same rate under the same conditions.

A thirty-fold increase in concentration of carbon dioxide only results in a four-fold assimilation, and although an increase in temperature results in an increase in assimilation-rate up to $25^{\circ} \mathrm{C}$., this appears to be the optimum temperature. Experiments have shown that total assimilation varies little with the latitude at which the vegetation grows.

Experiments were described with a number of plants such as barley, cotton, mangold and sugar beet, in which the net assimilation-rate in terms of drymatter increase per unit leaf area per unit time was determined. The results show that for these plants growing in very different environments and at different levels of nutrition, the net assimilation-rate varies only within narrow limits.

By burning the dry material in a bomb calorimeter, the energy content can be found, and by recording the varying intensity of radiation which has fallen on the plants over a period and knowing the mean leaf area, the efficiency of energy storage can be determined. This is of a low order, never exceeding 1.5 per cent for varying levels of manuring. It appears, therefore, that neither by varying the plant nor the fertility of the soil can the efficiency of energy accumulation be greatly changed, although the total quantity of dry matter can be increased if the total leaf surface is increased by more rapid development of the plants. 
There appears to be little hope that the efficiency of the photosynthetic process can be increased by selection or breeding.

On the basis of this information, Prof. Gregory considered the most effective methods of utilizing plant growth for storing solar energy. The most convenient product would be sugar or starch in the form of stored products in tubers or roots, which would be readily convertible to alcohol by fermentation processes. Prof. Gregory mentioned schemes which have been suggested for using micro-organisms, such as the green alga Chlorella, for the building up of chemical energy, and pointed out that there are so many difficulties that the use of higher plants with storage organs would appear more economical.

R. LoNG

\section{FUNCTIONS OF THE SKIN OF VERTEBRATES}

GECTIONS D (Zoology) and I (Physiology) of the $\checkmark$ British Association joined forces on the morning of September 1 to hear a group of papers on the functions of the skin.

Prof. P. B. Medawar (Birmingham) opened the session by discussing the anatomy of the mammalian epidermis, referring specially to the anatomical basis of pigmentary activity. He said that standard textbook diagrams of transverse sections of the skin are almost invariably at fault in their complete omission of the cells responsible for melanin formation-the cells variously called dendritic cells or epidermal melanoblasts or melanophores. Dendritic cells form a distinct lineage in the epidermis, and, as American work has shown, arise in development from the neural crest. The dendritic cell is the sole origin and seat of pigmentary function in the epidermis. In some manner the melanin formed within it is caused to enter into the cytoplasm of the Malpighian cells on which its branches end, a peculiar mode of secretion which Masson has called 'cytocrine'. Studies of whole mounts of pure epidermal sheets, treated with Methylene Blue or the Dopa reagent, reveal the shape, number and distribution of dendritic cells with conspicuous clarity. In particular, they reveal that dendritic cells, which are so distributed in the basal layer as to lie at arms' length from each other, often anastomose to form local syncytia.

Prof. Medawar recalled R. E. Billingham's demonstration that white and negro skins resemble each other in the number, form and distribution of their dendritic cells. The difference between them is merely functional : the dendritic cell of negro skin maintains the higher level of pigmentary activity. The same is true of the difference between red and black skin areas in patched guinea pigs.

In conclusion, Prof. Medawar asked for a revision of text-book diagrams of the anatomy of the epidermis, and said that British dermatologists might well revise, or at least reconsider, the histopathology of skin in the light of this newer knowledge of its anatomy.

Dr. J. D. Findlay and Mr. W. R. Beakley (Hannah Dairy Research Institute, Ayr) reported work which throws quite a new light on the problem of temperature regulation in cattle. Dr. Findlay put the question whether cows sweat-indeed, whether they have sweat glands at all. Deep in the dermis of cows' skin lie large, poorly vascularized, sac-like glands lined with myo-epithelial cells which pass a colloid secretion through ducts on to the skin surface ${ }^{1}$. These are commonly called sweat glands; but there is no evidence that they are instruments of temperature control.

The climatological room at the Hannah Institute was described by Dr. Findlay. The room was designed to study the mode of heat loss in cattle. It can be kept at any temperature between $20^{\circ}$ and $60^{\circ} \mathrm{C}$, and at almost any humidity, with or without air movement; and suitable instrumentation makes it possible to keep a continuous record of the respirationrate, heart-rate and skin-temperature of the calves kept in it. It has boen shown that, at a constant saturation deficit, the skin-temperature rises in direct proportion to the temperature of the environment: there is no flattening or drop at any level to suggest that sweating has begun. Peripheral vasodilatation in calf skin is probably already at maximum at $20^{\circ}$. Moreover, injections of pilocarpine or adrenaline, which provoke sweating in horses, have no such effect on calves.

Presumably, then, said Dr. Findlay, the cow loses heat from the skin primarily by radiation-unlike the horse, but probably like the dog and sheep. The cow is therefore not well adapted to tropical climates ; but, as Bonsma has shown, the cow best adapted as a radiator of heat is one with a glossy coat of light colour bearing short hairs with pigmented tips. It is noteworthy that tropical cattle like the zebu have the same skin structure as those from more temperate climates. One reason for their superior heat tolerance is probably the very large dewlap which, since it has a particularly dense network of cepillaries immediately below the skin surface, is probably an efficient extra radiator of heat.

Dr. W. S. Bullough (Sheffield) described his work on the replacement of the epidermis. Just as hairs might be replaced continuously, as in sheep, periodically, as in rats and mice, or seasonally, as in wild mammals, so the replacement of the epidermal layer is not a continuous and uniform process. There are recognizable patterns of replacement in space (for example, the anterior-posterior gradient of celldivision frequency in the skin of the mouse's back) and rhythms of replacement in time. All mice show a daily rhythm, and in female mice a rhythm in step with the cestrous cycle is superimposed on it.

Mitotic activity is high during natural or artificially induced sleep or at rest, and muscular activity is probably responsible for its fall by day. Injections of glucose or of phosphate before sleep raise the rate of cell division, and injections of phlorizin lower it. The blood-sugar level falls during rest, but significant quantities of glycogen are deposited in the skin as well as in the liver, and the rate of cell division at once rises. The facts, said Dr. Bullough, suggest that glycogen is the energy source that controls rate of cell division. It is noteworthy that although skin cultured in vitro in the absence of oxygen shows no new cell divisions, those started pass to completion. Oxygen, glycogen and phosphate all seem to act in advance of visible prophase-perhaps in an 'antephase' as little as fifteen minutes beforehand.

The general rise of mitotic activity during cestrus in female mice is no less conspicuous in the epidermis than elsewhere. Dr. Bullough suggested that oestrogen acts both directly, in influencing the frequency and completion-time of mitosis, and, indirectly, by mobilizing glycogen and causing its deposition in the epidermis, and by dilating the capillaries and perhaps increasing their permeability. The abundance of 